\title{
Effect of Dipping Basalt Fiber on Mechanical Properties of Concrete
}

\author{
Dingce Huang*, Qiu Xiong, Zhiwei Xing
}

Guangdong Meizhou Quality \& Metrology Supervision And Testing Instition, Binfang Avenue South 135, Meizhou 514072, P.R. China

*hhhuuuddd@sina.com

Key words: Fiber reinforced concrete, Basalt fiber, Epoxy resin, Flexural toughness

Abstract. A new dipping basalt fiber reinforced concrete (DBF-RC) was developed in this study. The surface of fiber was modified by dipping into epoxy resin. The mix of DBF was first researched on cement mortar, and then on concrete. The workability and mechanical properties of cementitious materials were investigated. Experimental results show that the optimum proportion of DBF is $1 \%$, and with this mix, the compressive strength, flexural strength and flexural toughness of concrete can be improved effectively.

\section{Introduction}

Concrete properties such as compressive strength, flexural strength, elastic modulus etc., are important in the service of structures. However, common concrete usually does not meet these requirements. For example, the highway bridge is expected to heavy compression and strong tension, resulting in cracks of concrete and the danger of life [1,2].

Fiber reinforced concrete (FRC) has superior mechanical properties with high performance fibers and low cost additives, which has been demonstrated by many researchers [3-5]. The addition of fibers in the concrete improves the fatigue resistance, flexural strength, toughness and tensile strength, as well as controls cracking [6]. Furthermore, the addition of fibers can reduce the overall cost of concrete production.

Basalt fiber is a fiber-material composed of minerals plagioclase, pyroxene, and olivine. It has good physical and mechanical properties of tensile strength, elastic modulus etc. But the price of basalt fiber is lower than other fibers. Due to the excellent properties, it is widely used in the areas of high pressure vessels, loading bearing profiles, concrete reinforcement etc.

Recent researches have used the basalt fiber to reinforce the mechanical properties of concrete [7, 8]. However, the mixing basalt fibers are not dispersed well and also reduce the fluidity of concrete, due to its affinity with water. In addition, the bonding between fiber and concrete is still required to improve.

This paper prepared a fiber reinforced concrete using basalt fiber dipped with epoxy resin. The effect of dipping basalt fiber on the workability, compressive strength and flexural strengths of cementitious materials was researched.

\section{Experimental}

Materials. The experimental basalt fiber has a diameter of $15 \mu \mathrm{m}$ and a length of $12 \mathrm{~mm}$, which indicates a large ratio of length to diameter. In addition, the fiber has good physical and mechanical properties, such as flexural strength, elastic modulus, ultimate elongation etc. More information about the properties of basalt fiber (BF) is listed in table 1.

Table 1 . The physical and mechanical properties of basalt fiber.

\begin{tabular}{cccccc}
\hline Materials & $\begin{array}{c}\text { Diameter } \\
(\mu \mathrm{m})\end{array}$ & $\begin{array}{c}\text { Length } \\
(\mathrm{mm})\end{array}$ & $\begin{array}{c}\text { Flexural strength } \\
(\mathrm{GPa})\end{array}$ & $\begin{array}{c}\text { Elastic modulus } \\
(\mathrm{GPa})\end{array}$ & $\begin{array}{c}\text { Ultimate } \\
\text { elongation }(\%)\end{array}$ \\
\hline $\begin{array}{c}\text { Basalt } \\
\text { fiber }\end{array}$ & 15 & 12 & $4 . .2 \sim 4.8$ & $93 \sim 110$ & 3.1 \\
\hline
\end{tabular}

The fiber had been dipped in epoxy resin to form a dipping basalt fiber (DBF) before experiment. The epoxy resin coating is hydrophobic, which can reduce water. In addition, the surface of the 
DBF is smoother than BF, making the fibers be easily mixed in concrete. Thus, with the dipping treatment, the workability and dispersion of fiber is improved. A comparison of the dispersion between BF and DBF is shown in Fig. 1. Furthermore, the coating enhances the flexural strength of fiber and improves the bonding strength with concrete.
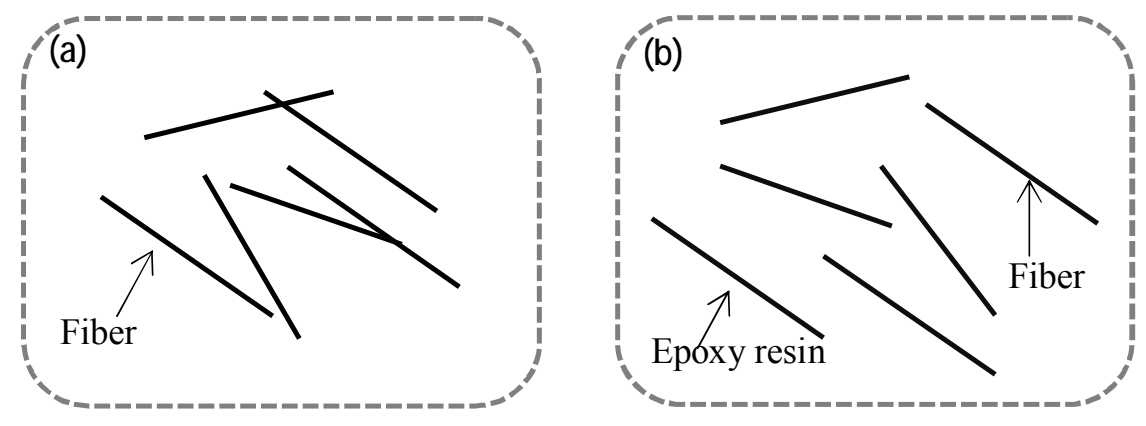

Fig. 1. Schematic diagram of the dispersion of (a) BFand (b) DBF in water.

A Portland cement ( $\mathrm{C}$ 42.5)) produced by the Huaxin Cement Co. Ltd. was used in the experiment. The secondary fly ash was used as mineral admixture. The fine aggregate had the fineness modulus of 2.8 with the bulk density of $1450 \mathrm{~kg} / \mathrm{m}^{3}$. The diameter of coarse aggregate was 5 31.5 mm.

Mixing Proportions and Forming. A water to cement $(\mathrm{w} / \mathrm{c})$ ratio of 0.5 was used for forming cement mortar. The mass ratio of cement: fly ash: sand was equal to $360 \mathrm{~g}: 90 \mathrm{~g}$ : $1350 \mathrm{~g}$. The size of mortar for compressive and flexural tests was $40 \mathrm{~mm}$ x $40 \mathrm{~mm}$ x $160 \mathrm{~mm}$.

The mix proportion of concrete is illustrated in table 2. A polycarboxylic acid was used for reducing water. The size of concrete for compressive test was $100 \mathrm{~mm}$ x $100 \mathrm{~mm}$ x $100 \mathrm{~mm}$. While that for flexural test was $100 \mathrm{~mm} \times 100 \mathrm{~mm}$ x $400 \mathrm{~mm}$.

Table 2. Mix proportion of concrete $\left(\mathrm{kg} \cdot \mathrm{m}^{-3}\right)$.

\begin{tabular}{cccccc}
\hline Cement & Fly ash & Fine aggregate & Coarse aggregate & Water & Water reducer \\
\hline 300 & 100 & 733 & 1146 & 148 & 4 \\
\hline
\end{tabular}

Methods of Testing. The fluidity of cement mortar was obtained according to the GB/T 2419-2005. Mechanical properties of compressive and flexural strengths were both investigated on mortar and concrete. Further research on the flexural property of concrete was done by flexural toughness test (Machine, Instron Model 1341).

\section{Results and Discussion}

Effect of DBF on Cement Mortar. Due to the similarity of composition and structure between mortar and concrete, cement mortar is in a sense a kind of fine aggregate concrete. Basic researches of the effect of dipping basalt fiber on mortar were done firstly before the mixing of DBF in concrete. Cement mortars with different DBF ratios of $0.5 \%, 1 \%$, and $1.5 \%$ were prepared, respectively. The curing age of cement mortars was 7 days. 


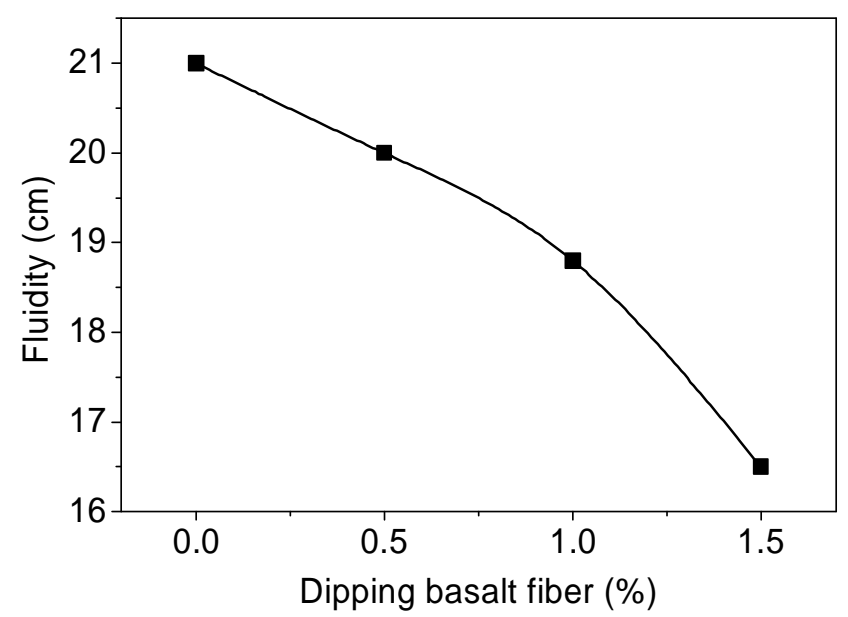

Fig. 2. Effect of DBF on the fluidity of cement mortar.

As shown in Fig. 2, the fluidity of cement mortars was decreased after mixed with DBF. The fluidity is in inverse proportion with the ratio of DBF. For the ratio of $1.5 \%$, the fluidity was decreased greatly. While mechanical properties of cement mortars were obviously improved, this is illustrated in Fig. 3. Considering both workability and mechanical property, the DBF ratio of 1\% is proper for use.

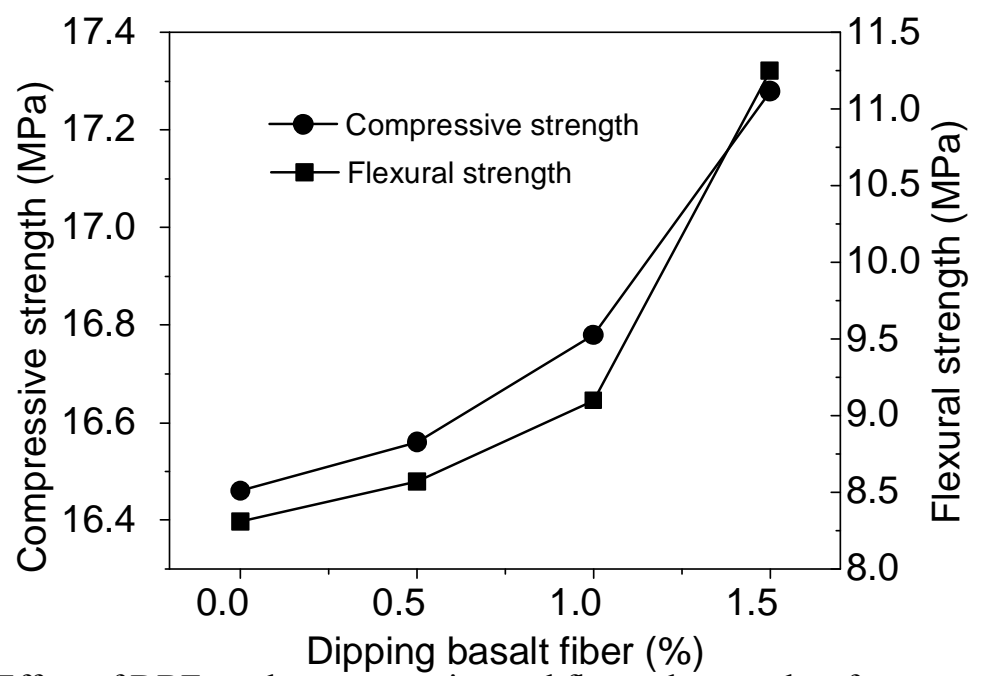

Fig. 3. Effect of DBF on the compressive and flexural strengths of cement mortar.

Based on the study of mortar, the mixing proportion of $1 \%$ was chosen to form a dipping basalt fiber reinforced concrete (DBF-RC). And then the mechanical properties of DBF-RC would be researched.

Compressive and Flexural Strengths of DBF-RC. A normal concrete and DCF(1\%) reinforced concrete (DBF-RC) were compared in this research. The compressive and flexural properties were investigated at the curing ages of $3 \mathrm{~d}, 7 \mathrm{~d}$ and $28 \mathrm{~d}$. 

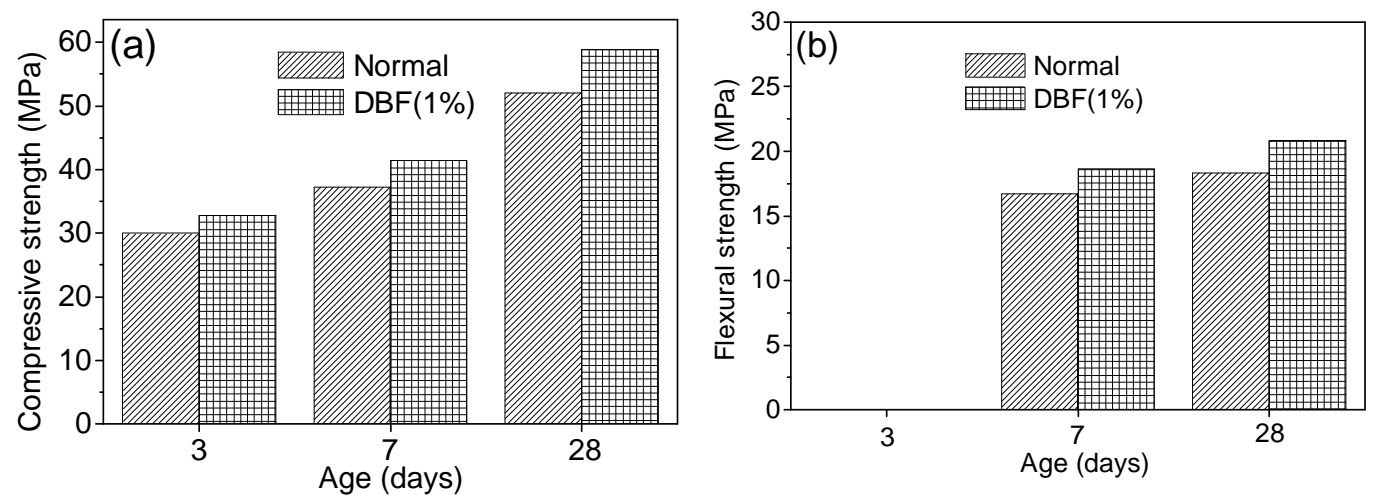

Fig. 4. Influence of DBF on (a) compressive and (b) flexural strengths of concrete

As depicted in Fig. 4, compared with the normal concrete, the compressive strength of DBF-reinforced concrete was increased by $8.7 \%, 10.1 \%$ and $13.3 \%$ at the ages of $3 \mathrm{~d}, 7 \mathrm{~d}$ and $28 \mathrm{~d}$, respectively. The $3 \mathrm{~d}$ flexural strength was too weak, and was not easy to measure. The flexural strengths of $7 \mathrm{~d}$ and $28 \mathrm{~d}$ were increased by $11.6 \%$ and $14.1 \%$, respectively. The data result shows that DBF has a greater influence on flexural strength than compressive strength.

Flexural Toughness Test. Fig. 5 shows the deflection curves of normal concrete and DBF-RC. The deflection of DBF-RC is $0.476 \mathrm{~mm}$. While for normal concrete is $0.448 \mathrm{~mm}$. Parameters of the flexural toughness are listed in table 3. Compared with normal concrete, the DBF-RC has a higher bearing capacity, and requires more power to be destructed. The elastic modulus data shows the deformability of DBF-RC is better than normal concrete.
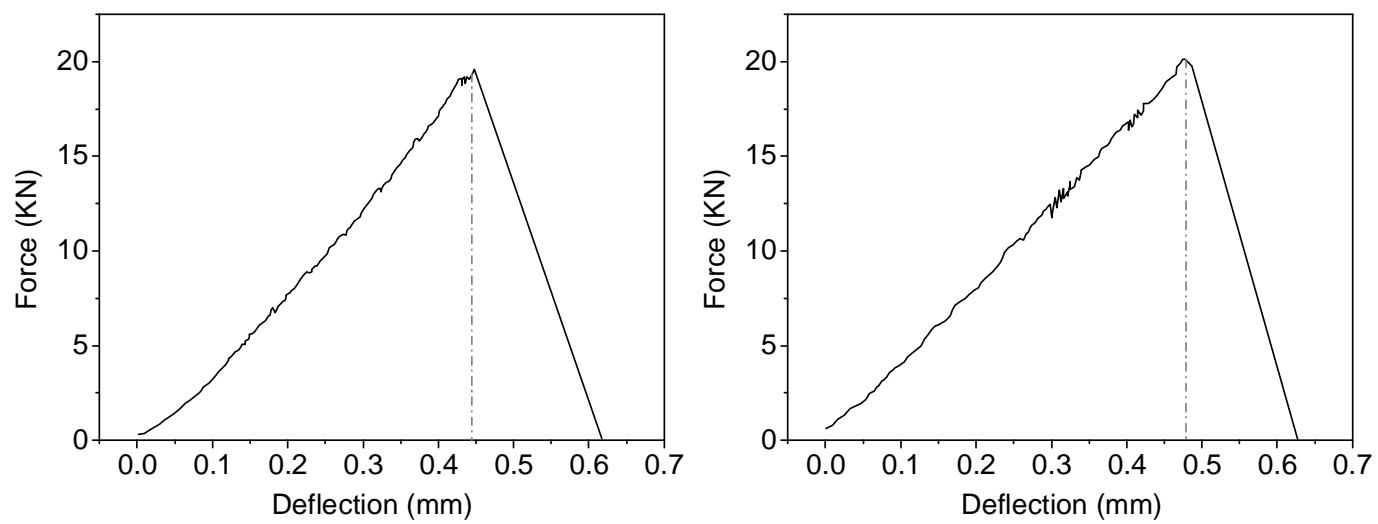

Fig. 5. Influence of DBF on the deflection of concrete.

Table 3. Parameters of the flexural toughness test.

\begin{tabular}{lccccc}
\hline Samples & $\begin{array}{c}\text { Max. load } \\
(\mathrm{KN})\end{array}$ & $\begin{array}{c}\text { Max. yield } \\
\text { strength }(\mathrm{Mpa})\end{array}$ & $\begin{array}{c}\text { Elastic modulus } \\
(\mathrm{Mpa})\end{array}$ & $\begin{array}{c}\text { Yield } \\
\text { power }(\mathrm{J})\end{array}$ & $\begin{array}{c}\text { Destruction } \\
\text { power }(\mathrm{J})\end{array}$ \\
\hline Normal & 16.88 & 5.06 & 3305.89 & 3.39 & 3.71 \\
DBF $(1 \%)$ & 20.79 & 6.24 & 3104.47 & 6.56 & 7.85 \\
\hline
\end{tabular}

\section{Conclusions}

The effect of dipping basalt fiber on the mechanical properties of cementitious materials was researched in this research. Fibers dipping with epoxy resin have better dispersive and bonding abilities. The optimum proportion of DBF and its influence on mechanical properties of concrete were investigated. 


\section{Acknowledgements}

This research has been financially supported by the National Natural Science Foundation of China (project 51272194, 51208398), the Fundamental Research Funds for the Central Universities (WUT:142201001), the Fundamental Research on mitigating sulfate attack reaction of concrete with LDHs from State Key Laboratory of Silicate Materials for Architectures of Wuhan University of Technology (SYSJJ2014-03).

\section{References}

[1] Thomas T. C. Hsu, Floyd O. Slate, Gerald M. Sturman, and George Winter, Microcracking of plain concrete and the shape of the stress-strain curve, Journal Proceedings 60 (1963) 209-224.

[2] K Babaei, A.M. Fouladgar, Solutions to concrete bridge deck cracking, Concrete International 19 (1997) 34-37.

[3] M. Sun, et al., A study of piezoelectric properties of carbon fiber reinforced concrete and plain cement paste during dynamic loading, Cement and Concrete Research 30 (2000) 1593-1595.

[4] L. Ferrara, Y.-D. Park, and S.P. Shah, A method for mix-design of fiber-reinforced self-compacting concrete, Cement and Concrete Research 37 (2007) 957-971.

[5] G. Chanvillard, Modeling the pullout of wire-drawn steel fibers, Cement and Concrete Research 29 (1999) 1027-1037.

[6] A. Sivakumar, Manu Santhanam, Mechanical properties of high strength concrete reinforced with metallic and non-metallic fibres, Cement and Concrete Composites 29 (2007) 603-608.

[7] Jongsung Sim, Cheolwoo Park, Characteristics of basalt fiber as a strengthening material for concrete structures, Hanyang University, South Korea, 425-791,.

[8] Dias D P, Thaumaturgo C, Fracture toughness of geopolymeric concretes reinforced with basalt fibers, Cement and Concrete Composites 27 (2005) 49-54.

[9] Czigany T, Poloskei K, Karger-Kocsis J, Fracture and failure behavior of basalt fiber mat-reinforced vinyl ester/epoxy hybrid resins as a function of resin composition and fiber surface treatment, Journal of materials science 40 (2005) 5609-5618. 